\title{
Construction and Reform of Course System for Economic Mathematics Experiment on Local Universities of Finance and Economics
}

\author{
Feng Youling \\ School of Management Science and Information \\ Engineering \\ Jilin Province Key Laboratory of Internet Finance \\ Jilin University of Finance and Economics \\ Changchun, China \\ e-mail: fengyouling79@163.com

\section{Mu Guangyu} \\ School of Management Science and Information \\ Engineering \\ Jilin Province Key Laboratory of Internet Finance, \\ Jilin University of Finance and Economics, \\ Changchun, China \\ e-mail:335620599@qq.com

\section{Wang Limin} \\ School of Management Science and Information \\ Engineering \\ Jilin Province Key Laboratory of Internet Finance \\ Jilin University of Finance and Economics \\ Changchun, China \\ e-mail: wanglimin_new@126.com

\section{Cao Zhongbo} \\ School of Management Science and Information \\ Engineering \\ Jilin Province Key Laboratory of Internet Finance \\ Jilin University of Finance and Economics \\ Changchun, China \\ e-mail: caozhongbo@jlufe.edu.cn
}

\author{
Chen Yao \\ Department of Applied Mathematics \\ Jilin University of Finance and Economics \\ Changchun, China \\ e-mail: 973795299@qq.com
}

\author{
Kang Jing \\ Department of Applied Mathematics \\ Jilin University of Finance and Economics \\ Changchun, China \\ e-mail: 1751589800@qq.com
}

\author{
Yu Zhuoxi \\ School of Management Science and Information \\ Engineering \\ Jilin Province Key Laboratory of Internet Finance \\ Jilin University of Finance and Economics \\ Changchun, China \\ e-mail:719229899@qq.com
}

\author{
Sun Tiezheng \\ School of Management Science and Information \\ Engineering \\ Jilin Province Key Laboratory of Internet Finance \\ Jilin University of Finance and Economics \\ Changchun, China \\ e-mail: suntiezheng@yeah.net
}

\section{INTRODUCTION}

Abstract-The college graduates from financial universities should have professional knowledge and comprehensive quality to dealing with big data. It requires more reasonable economical mathematics experiment courses. Take Jilin University of Finance and Economics as example. From talents training on different objective, we have established an experimental curriculum of economic mathematics, which is called "One Main Shaft with Four-wheel Driving". Furthermore we have reformed totally in practical course system.

Keywords-four-wheel driving, different level, different specialized subject, curriculum module, reformatory practice
Mathematics is related to all around the fields in society. It provides us ideas and methods for solving problems. As an indispensable tool, math plays an important role in making economic forecasting and decision-making. As done in Jilin University of Finance and Economics abbreviated to "JLUFE" in the following. The construction of course system for economical mathematics and its experiment is built up by different levels and specialized subjects. According to characteristics and teaching object, the course system is divided into four modules which are basic courses in general education, discipline basic course, professional curriculum and integrated practice. 
In traditional, educators emphasize the integrity and basic knowledge, theoretical derivation and so on. In economic environment, talents should be focused on the cultivation of innovative and comprehensive abilities; Education are oriented by examination; Teachers are protagonists; Students develop in single direction, just accept from teachers and study independently; Trans-information is unitary; Most teaching background is artificial. Our goal is to transform the traditional examination oriented education to modern quality. The characteristics of the curriculum is student-centered, multidirection development, cooperation study, inquiry learning state, exchange of information, simulation teaching background and real living situations. The renewal of educational ideas has brought challenges to teachers. They must promote the educational methods.

\section{REASONABLE CONSTRUCTION OF CURRICULUM SYSTEM}

At present, economic mathematics experiments courses have been paid more and more attention as a bridges from mathematics to economic management[1]. Take Jilin University of Finance and Economics as example. We have made a reasonable economic mathematics experiment curriculum for talents training goal.

\section{A. Offer Courses by layer and professional}

According to training goal of local finance and economics universities, majors are divided into three types: professional type, compound type and applied type. The curriculum, teaching content and difficulty of courses are determined by different types.

Applied mathematics and statistics belongs to the professional type. Students in these majors are required to mast mathematics theory, experiment and creative abilities.

Students majored in math should be good at mathematical theory. In addition to mathematical modeling and experiments, we also arranged the risk theory and other auxiliary courses to train students with excellent mathematical ability and good economic theory[2].

The training objective of statistics professional is requiring students to use software, do data collection skillfully, do analysis in high level such as statistical applications and research work of composite statistical professionals. The school opened a professional statistical laboratory, the application of regression analysis, optimization theory and methods, etc. (As shown in Fig. 1)

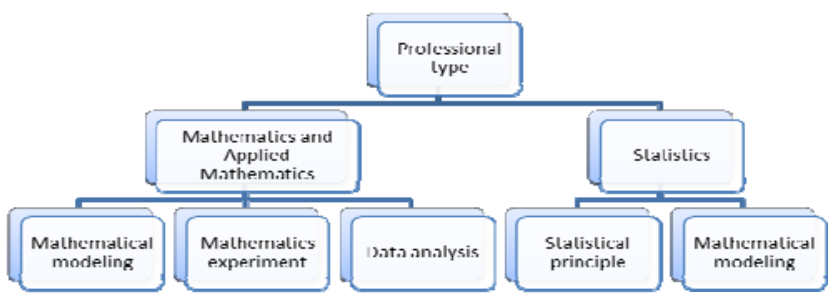

Fig. 1. Subject setting on professional type
The compound type refers to computer science and technology (financial engineering) and management information and information systems professional. According to these professionals, students should be taught mathematical methods with professional background and skills.

For instance, students majored in computer science and technology learns modeling methods and application. They should pay more attention to the integration of mathematics and computer technology. Teachers are required to provide a variety of cases to satisfy students.

Financial engineering students need to mast ability of analyzing the financial market. We design innovation, risk management, mathematical modeling and other courses for them. The goal of information management and information system is to training ability of obtaining modern information theory, information processing, information management technology and economic information processing. Thus, we set up management software development foundation, statistics, management operations research and other courses. (As shown in Fig. 2)

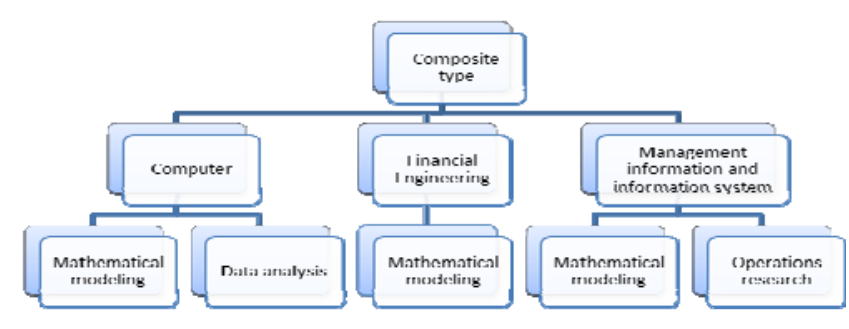

Fig. 2. Subject setting on compound type

The application type covers the Electronic Commerce and Taxation. Teachers mainly teach basic mathematical methods and models in application. The students majored in Electronic Commerce are required to grasp the ability of mathematics analysis, network technology fusion, the solid quantity analysis theory and the management basic knowledge. Students majored in Taxation need to be familiar with tax and relevant economic theories. We opened the course of mathematical modeling to help students master the tax engineering, taxation case analysis and auxiliary course in JLUFE. (As shown in Fig. 3)

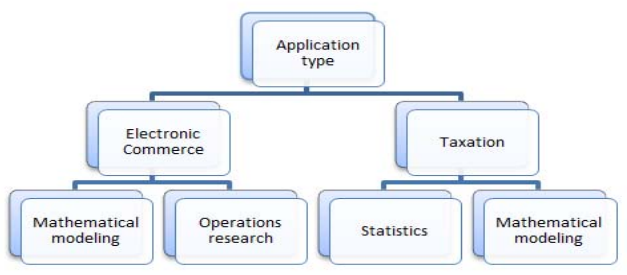

Fig. 3. Subject setting on application type

Mathematical models playing an important role in engineering technology, natural science and mathematics fields. Because they reflect the essence of problems which are tools integrated into human complex analysis but not simple copies. 


\section{B. “One Main Shaft with Four-wheel Driving”models}

We construct the course layout of "One Main Shaft with Four-wheel Driving". "One Main Shaft" means that cultivating innovative talents is a main shaft. "Four-wheel Driving" means that the economic Mathematical Experiment course is divided into four modules, such as general basic module, subject based module, specialized courses module and comprehensive practice module. And curriculums are designed to different module types for various specialties. (As shown in Fig. 4)

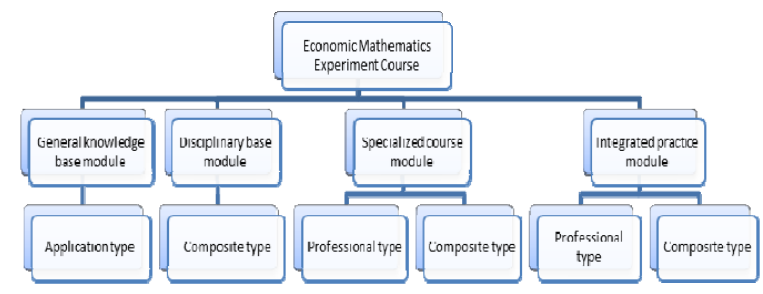

Fig. 4. Curriculum module setting

General education module is the key part to realize the goal of general education, and it is the most effective way to achieve the quality education. This module is mainly "educating" instead of "teaching". The basic theory is theories and skills related to natural science, humanities and social science.

The module of professional curriculum should be wellmatched to the basic module. It includes basic theory, professional knowledge and professional skills. For students in Mathematics, Statistics, Computer and other professional in data analysis and software operation, they should grasp mathematical methods in professional level and ability dealing with data.

Comprehensive practice module covers the practice courses for students' self-study by guidance of teachers. For instance, students majored in Mathematics and Applied Mathematics is both professional and complex type. The application of knowledge trains the students' practice and innovation ability.

\section{TOTAL REFORM AND PRACTICE OF CURRICULUM SYSTEM}

\section{A. Cultivate innovative talents by classroom teaching}

The teaching outline is an important part for personnel training programs to achieve the teaching goal. It is an important basis for teaching organization and quality assessment. Knowledge, quality and ability can guarantee the teachers teaching quality[3]. In order to meet the professional teaching and personnel training objectives, teaching plans have been formulated to different profession. The students' focus on mathematics applying has been developed. We pay attention to the combination of technology and economic mathematics. The main contents of Economic Mathematics Experiment are processing the economic data. Students can understand the problem and solve practical problems by learning those contents.

Practical courses and theoretical courses are different. We take the teaching method of "group discussion model"[4-6]. At beginning of term, students formed a team with a leader. The course work was completed by team members cooperatively. The practical homework is assigned to team members, and the main ideas and modeling process was explained and shared with the class. This teaching model has ensured student to obtain overall training, to promote each other and to make common progress.

To clear the talents training goal, the cultivation of compound talents require not only the socialist market economy but also the times[7]. It make students realize their self-value and dignity, stimulate their interest and accomplishment in Mathematics. Meanwhile, we focus on the intersection and infiltration of subjects, training the ability of practicing, learning and cooperating in mathematics teaching practice.

The examination mode was reformed by final paper with the implementation process of proposal, thesis writing and replying way to obtain the final grade. This mode can lay a basis for students to write thesis in the future.

\section{B. Students centered practice model}

In class, students are provided a large number of cases, demanded to analyze, discuss the case fully and do some research work. Each course experiment is completed by team in form of report. The homework is submitted online and the course resources are used fully online. Social survey work was arranged according to the classroom content. The students are grouped by researching, writing the survey report and experiencing. And they are given fully initiative chance so that their potential learning can be excavated deeply.

\section{INNOVATION AND REFORM EFFECT EVALUATION}

We reformed and practiced the innovative teaching mode. The comprehensive ability of students is more and more outstanding and students' interest has been aroused[8].

In addition to Jilin province and China Undergraduate Mathematical Contest in Modeling, JLUFE has also been significantly improved in other practical contests in recent years. For example, we achieved a breakthrough from scratch in the 2015th America Undergraduate Mathematical Contest in modeling[9]. It is the first year that we attended this contest. Obviously, students' ability is growing rapidly in the innovation contest. This is closely linked with implementation of the Mathematics Experiment curriculum reform in JLUFE.

\section{The Future Needs to Solve the Problem}

In big data and network era, it is very important to share and utilize the resources effectively. Most teachers in local financial universities have not fully utilized and developed educational resources. They are failed to form an optimal allocation of educational resources and effective recycling. They have not realized the transformation from tacit knowledge to explicit knowledge, and failed to make students acquire more knowledge out-of-book. To solve these problems, we should enhance teacher's professional learning and improve the scientific literacy harder[10]; Teachers should improve 
their teaching methods, recommend their practical experience and enhance the efficiency of classroom teaching.

With the effective development of the discipline competition, the condition of the field, equipment and so on are improved. Limited by funds and qualified teachers, universities has some problems in software and hardware in discipline competition. This leads students lacking of competition. To solve this problem, the school should open a number of laboratories in spare time so that students' practical activities can be satisfied. Therefore, we should vigorously promote the reform of teaching mode and enhance the teachers' professional guidance ability, strengthen the business training continuously.

\section{CONCLUSION}

We construct the course system for economic mathematics experiment by different level and specialized subject. It includes four modules: basic courses in general education, discipline basic course, professional curriculum and integrated practice. The reforms of teaching make students have good professional quality and rich experience.

\section{ACKNOWLEDGMENT}

This work was supported by NSFC(11601181), NSSF(15BGL090), Teaching of Higher Education in Jilin Province "Educational Reform and Practice of Economic Mathematics Experiment Course System on the Local Finance and Economics University". The Planning Project of Jilin Province Education Scientific (GH150284, GH150655, GH150287,GH14219,2015ZCY126). Projects for Social Sciences of Jilin Province (2016075). National Education
Science "12th Five-Year" Key Projects of the Ministry of Education (DIA110262).

\section{REFERENCES}

[1] Wang Yang,Ding Xiangdong,Guo Min.Based on the improvement of students' learning efficiency of the course scheduling model[J].Science \& Technology Information, 2014(02),pp.54-55.

[2] Baidu Encyclopedia. mathematical modeling.http://baike.baidu.com/link?url=hNOIm1cBQuC41OYb81xKbt yoWgP7dMX-u1FdMX6aWla65xfOz 6r0WZmeGmIpkDKKZIjbta_EJTvnsWRud152v_1GGGqWeAIZ7vz2arjD-S

[3] Xu Bihuan, Zhang Yingzhou, Chen Lei. Exploration on teaching reform of "advanced mathematics" in "Excellence program"--Take computer science and technology specialty as an example[J].Education and Teaching Research,2016(05),pp.87-95

[4] Chen Lihua,Cao Kesheng,Ma Wei,Liu Qiaoru,Zhao Xuyao,Gao Huashan. The embodiment of application oriented Talents Cultivation in the teaching reform of Biochemistry Course[J].Guangzhou Chemical Industry, 2016(04),pp.162-164

[5] Ni Jiangli,Huang Wenjuan,Su Lei. Reform and practice of College Physics Teaching in Applied Universities -- a case study of Anhui College[J]. Cathay Teacher,2015(12),pp.50-51

[6] Yang Dongmei,Wang Jun. The green reform of Physical Chemistry Experiment Teaching [J].University Education,2016(01),pp.90-92

[7] Dong Zefang. Definition and analysis of the concept of talent cultivation mode in Colleges and Universities[J].University Education Science,2012(03),pp.30-35

[8] Xie Jingxing. Scientific organization of College Students' mathematical modeling contest, promoting the cultivation of innovative talents and the reform of Mathematics Education[J]. Education and Teaching Research,2009(2),pp.8-11.

[9] www.mom.edu.cn

[10] Wang Liying. Research on the competition and teaching mode of College Students' mathematical modeling[J]. Intelligence,2014(5),pp.56 